\title{
Photovoltaic efficiency enhancement of polycrystalline silicon solar cells by a highly stable luminescent film
}

\author{
Yuan Wang ${ }^{1}$, Paula Gawryszewska-Wilczynsk ${ }^{2}$, Xiurong Zhang ${ }^{3,4}$, Jian Yin ${ }^{3,4}$, Yongqing Wen ${ }^{3,4}$ and \\ Huanrong $\mathrm{Li}^{1 *}$
}

\begin{abstract}
Si-based solar cells have dominated the entire photovoltaic market, but remain suffering from low power conversion efficiency (PCE), partly because of the poor utilization of ultraviolet (UV) light. Europium(III) $\left(\mathrm{Eu}^{3+}\right)$ complexes with organic ligands are capable of converting UV light into strong visible light, which makes them ideal light converter to increase the efficiency of solar cells. However, the low stability of such complexes seriously hampers their practical applications. In this work, we report a highly stable and luminescent ethylene-vinyl acetate (EVA) copolymer film consisting of a $\mathrm{Eu}^{3+}$ complex as a down-shift material, Eu (ND) ${ }_{4}$ CTAC (ND = 4-hydroxy-2-methyl-1,5-naphthyridine-3carbonitrile, CTAC = hexadecyl trimethyl ammonium chloride), coating of which onto the surface of large area polycrystalline silicon solar cells (active area: $110 \mathrm{~cm}^{2}$ ) results in an increase of PCE from $15.06 \%$ to $15.57 \%$. Remarkable stability of the luminescent film was also demonstrated under lightsoaking test for $500 \mathrm{~h}$, and no obvious luminescence degradation can be observed. The remarkable enhancement of the conversion efficiency by $0.51 \%$ absolute on such a large active area, together with the high stability of the luminescent film, demonstrates a prospect for the implementation of the films in photovoltaic industry.
\end{abstract}

Keywords: ethylene-vinyl acetate, lanthanide complexes, solar cell, stability

\section{INTRODUCTION}

Nowadays, fossil fuels are still the main source for covering the energy demands for humanity's economic development. As the increasing energy requirement will lead to the ultimate depletion of fossil fuels, there is an urgent need for exploring renewable energy sources. Therefore, scientists are turning their attention to solar energy for its inexhaustibility and environmental friendliness $[1,2]$. The utilization of solar energy includes both photo-thermal conversion and photoelectric conversion, in which photovoltaic cells that employ semiconductor materials to convert light into electricity are a promising candidate for the new dominant energy source in the future $[3,4]$. Presently, silicon-based solar cells account for $95 \%$ of the photovoltaic market. According to the Shockley-Queisser efficiency limitation, the maximum efficiency value of silicon-based solar cells is about $31 \%$. However, the actual power conversion efficiency (PCE) is relatively lower than the theoretical value, limiting their long-term development [5-7]. In general, there are three main factors that limit the energy conversion efficiency: a) Lattice thermalization loss, where high-energy photons are absorbed by solar cells and then produce one electron-hole pair, while the excess energy is dissipated through non-radiative relaxation as heat. b) Sub-bandgap photon loss, where photon energy is too small to cross the energy bandgap threshold energy, so that no electronhole pairs are generated. c) The loss from electronic properties of the device, such as the loss of recombination of electron-hole pairs from surface, contact voltage loss, and junction loss $[5,8]$. The first two energy-conversion loss mechanisms are directly related to the spectral mismatch between solar spectrum and bandgap of the silicon-based material. The last loss process depends on the fabrication of solar cell devices. The strategy of spectrum

\footnotetext{
${ }^{1}$ School of Chemical Engineering and Technology, Hebei University of Technology, Tianjin 300130, China

${ }^{2}$ Faculty of Chemistry, University of Wroclaw, 14F. Joliot-Curie Str., 50-383 Wroclaw, Poland

${ }^{3}$ Tianjin Baogang Research Institute of Rare Earths Co., Ltd., Tianjin 300300, China

${ }^{4}$ State Key Laboratory of Baiyunobo Rare Earth Resource Researches and Comprehensive Utilization, Baotou 014030, China

* Corresponding author (email: lihuanrong@hebut.edu.cn)
} 
modification associated with spectral mismatch like down-conversion, down-shift or up-conversion can optimize the conversion efficiency of solar cells, which also reduces the long-term cost of solar cell construction [9$14]$.

The technology of down-shift that involves absorbing one higher energy photon and releasing one photon of lower energy is considered as an effective approach to reduce the thermalization loss $[6,15]$. Usually, a practical and intriguing method to utilize this technology is to embed down-shift materials into polymer matrices such as polyvinyl alcohol, ethylene-vinyl acetate (EVA) and polymethyl methacrylate, after which the polymer matrices are attached on the surface or encapsulated inside of photovoltaic modules for enhancing the conversion efficiency [16-18]. In this context, lanthanide complexes constituted of lanthanide ions and organic ligands, exhibiting favorable luminescent features such as a large Stokes shift, narrow emission bands and longer decay times, are promising down-shift candidates [19,20]. A wide range absorption of organic ligands in the UV region can lead to efficient energy transfer to the lanthanide ions and trigger strong luminescence, simultaneously also attenuating polymer matrix long-term degradation caused by UV irradiation [21-24]. In particular, the dominant emission of $\mathrm{Eu}^{3+}$ at $612 \mathrm{~nm}$ is very close to the maximum spectral sensitivity of crystalline Si-based solar cells [25-32]. For instance, Fix and co-workers [33] have summarized a series of promising $\mathrm{Eu}^{3+}$ complexes as down-shift species that exhibit an improvement of PCE, but the stability issue remains a challenge. In terms of the $\left[\mathrm{Eu}(\mathrm{tta})_{3}(\mathrm{tppo})_{2}\right]$ complex, it was found to be only stable for several hours upon illumination with $350 \mathrm{~nm} \mathrm{UV}$ light [34]. The intrinsic disadvantages of lanthanide complexes such as low thermal and photochemical stability, especially photodegradation of the sensitizer upon UV exposure, limit their photovoltaic application. Hence, engineering of lanthanide complexes with impressive stability and high quantum efficiency is paramount for further development of this technology.

Herein, we demonstrate the increase in PCE of polycrystalline silicon solar cells by coating EVA film containing europium(III) complex (Eu(ND) ${ }_{4}$ CTAC) [35] on the surface of the devices (active area: $110 \mathrm{~cm}^{2}$ ). By downshifting higher energy photons, the obtained luminescent film (denoted as $\mathrm{Eu}(\mathrm{ND}){ }_{4} \mathrm{CTAC} / \mathrm{EVA}$ film) can be better to utilize the AM 1.5G spectrum. A series of luminescent films with varying complex concentrations have been compared and studied in photovoltaic characterization. The results show that in the best case, the PCE of poly- crystalline silicon solar cells increases from $15.06 \%$ to $15.57 \%$ by using the luminescent film. The obtained luminescent films display excellent photostability, almost keeping the luminescence intensity unchanged even under continuous UV radiation at $30^{\circ} \mathrm{C}$ for $500 \mathrm{~h}$. The realization of employing stable $\mathrm{Eu}(\mathrm{ND}){ }_{4} \mathrm{CTAC} / \mathrm{EVA}$ film as a medium to enhance the PCE of Si-based solar cells demonstrated here makes it attractive for photovoltaic industry.

\section{EXPERIMENTAL SECTION}

\section{Materials}

EVA copolymer (LG ES28005), toluene and dichloromethane were used as received. Eu(ND) ${ }_{4}$ CTAC (ND = 4-hydroxy-2-methyl-1,5-naphthyridine-3-carbonitrile, CTAC = hexadecyl trimethyl ammonium chloride) was obtained from Beijing Boda Green Technology Co., Ltd. and the structure was confirmed by elemental analysis and ${ }^{1} \mathrm{H}$ NMR spectrum as shown in Table S1 and Fig. S1. Si-based solar cells were provided by Xinao Photovoltaic Energy Co., Ltd.

\section{Preparation of $\mathrm{Eu}(\mathrm{ND})_{4} \mathrm{CTAC} / \mathrm{EVA}$ films}

Dichloromethane solutions of $\mathrm{Eu}(\mathrm{ND})_{4} \mathrm{CTAC}$ complexes (7.2-54 mg) at different concentrations were prepared. $3.6 \mathrm{~g}$ of EVA pellets was dissolved in toluene $(24 \mathrm{~g})$ at $60^{\circ} \mathrm{C}$ for $2 \mathrm{~h}$ with stirring. The aforementioned solutions were separately mixed in an ultrasonic bath, after which the solution was poured into a Petri dish $(170 \mathrm{~mm})$ and dried at $80^{\circ} \mathrm{C}$ for several hours, resulting in luminescent polymer composite films. Pure EVA film was obtained using the same method as described above, without the addition of $\mathrm{Eu}(\mathrm{ND}){ }_{4} \mathrm{CTAC}$ complex. Subsequently, the weight $\%$ relative value was used to indicate the concentration of $\mathrm{Eu}(\mathrm{ND})_{4} \mathrm{CTAC}$ complex relative to EVA $(0.2 \%, 0.5 \%, 0.7 \%, 1 \%$ and $1.5 \%)$.

\section{Characterizations}

${ }^{1} \mathrm{H}$ NMR spectrum was recorded in $\mathrm{CDCl}_{3}$ using a Bruker ARX 400 spectrometer. Elemental analyses (C, H and N) were measured with an Elementary Vario EI. The fluorescence data were obtained by using an Edinburgh Instruments FS920P spectrophotometer. Scanning electron microscopy (SEM) measurement was carried out with an S-4800 at a voltage of $3 \mathrm{kV}$. Light transmittance of the films and UV absorbance spectra of the samples were measured with an Agilent Cary $100 \mathrm{UV}$-Vis spectrometer. The thermal stability was studied by thermogravimetric analysis by using a SDT Q600 TGA in ambient air at- 
mosphere at a heating rate of $10^{\circ} \mathrm{C} \mathrm{min}^{-1}$. Photo stability was studied by a UV aging test under $160 \mu \mathrm{W} \mathrm{cm}{ }^{-2}$ irradiance at $30^{\circ} \mathrm{C}$ for $500 \mathrm{~h}$. For the characterization of the photovoltaic solar cell performance, different EVA/complex films were directly coated on top of a Si-based solar cell (active area: $110 \mathrm{~cm}^{2}$ ). External quantum efficiency (EQE) measurement and photocurrent-voltage characteristics were recorded by using a QEX10 PV measurement system and a Newport IV30 solar simulator at AM 1.5G conditions, respectively.

\section{RESULTS AND DISCUSSION}

The structure of the complex Eu(ND) ${ }_{4} \mathrm{CTAC}$ is shown in Scheme 1, where each Eu atom is linked to four ND ligands and one hexadecyltrimethylammonium ion. Transparent $\mathrm{Eu}(\mathrm{ND})_{4} \mathrm{CTAC} / \mathrm{EVA}$ films containing different concentrations of the $\mathrm{Eu}(\mathrm{ND})_{4} \mathrm{CTAC}$ complex $(0.2 \%, 0.5 \%, 0.7 \%, 1 \%$ and $1.5 \%)$ were prepared by the solution-casting approach [25]. Selecting EVA as the matrix for down-shift materials is motivated by its strong adhesion and excellent light transparency in relation to glass. In fact, EVA usually plays the role of sealer material in the whole process of encapsulating Si-based solar

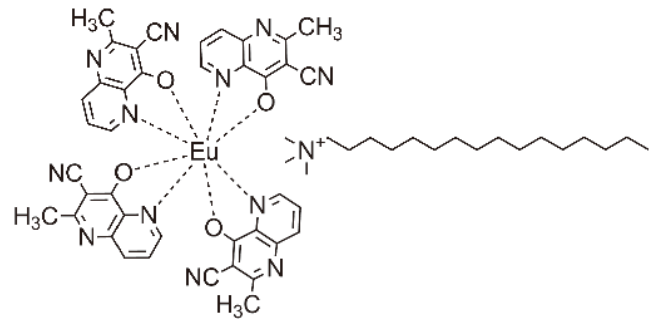

Scheme 1 Structural formula of the $\mathrm{Eu}^{3+}$-compound used in this study.

modules in photovoltaic industry, which provides an opportunity to facilitate the application at production scale [36].

As the first step, the photoluminescent properties of the resulting films were studied. As shown in Fig. 1a, the emission spectrum of Eu(ND) ${ }_{4}$ CTAC/EVA film, excited at $356 \mathrm{~nm}$, is composed of five sharp bands at 579,590 , 613,652 and $702 \mathrm{~nm}$, ascribed to the ${ }^{5} \mathrm{D}_{0} \rightarrow{ }^{7} \mathrm{~F}_{\mathrm{J}}(J=0-4)$ transitions, respectively. The presence of the ${ }^{5} \mathrm{D}_{0} \rightarrow{ }^{7} \mathrm{~F}_{0}$ transition indicates a low point symmetry of the surroundings of the $\mathrm{Eu}^{3+}$ ion $\left(C_{n v}, C_{n}\right.$ or $C_{s}$ symmetry). On the other hand, the low intensity of the ${ }^{5} \mathrm{D}_{0} \rightarrow{ }^{7} \mathrm{~F}_{3}$ transition, which is forbidden as an electric dipole and


Figure 1 (a) Excitation and emission spectra of Eu(ND) ${ }_{4} \mathrm{CTAC} / \mathrm{EVA}$ film (0.7\%). (b) Emission spectra of Eu(ND) $)_{4} \mathrm{CTAC} / \mathrm{EVA}$ films with different concentrations of $\mathrm{Eu}(\mathrm{ND})_{4} \mathrm{CTAC}$ complex. Digital photographs of Eu(ND) ${ }_{4} \mathrm{CTAC} / \mathrm{EVA}$ film $(0.7 \%)$ under daylight (c) and UV irradiation at $365 \mathrm{~nm}(\mathrm{~d})$. 
magnetic dipole transition, indicates a small participation of J-mixing in the intensity of $\mathrm{f}-\mathrm{f}$ transitions in this system. The main band dominated by the ${ }^{5} \mathrm{D}_{0} \rightarrow{ }^{7} \mathrm{~F}_{2}$ transition at $613 \mathrm{~nm}$ is responsible for the strong red luminescence [37]. The excitation spectrum obtained by monitoring the absorbance under the $613 \mathrm{~nm}$ wavelength exhibits a broad band in the region from 265 to $388 \mathrm{~nm}$ attributed to the absorption of the ND ligand, which is almost overlapped with the $n-\pi^{*}$ transition present in the absorption spectrum (Fig. 2 and Fig. S2). This observation confirms the occurrence of energy transfer from the $\mathrm{ND}$ ligand to $\mathrm{Eu}^{3+}$. In addition, the emission spectra of $\mathrm{Eu}(\mathrm{ND}){ }_{4} \mathrm{CTAC} / \mathrm{EVA}$ films with different $\mathrm{Eu}(\mathrm{ND}){ }_{4} \mathrm{CTAC}$ concentrations from $0.2 \%$ to $1.5 \%$ were measured as shown in Fig. 1b, revealing that the luminescence intensity increases along with the concentration of the Eu (ND) ${ }_{4}$ CTAC complex. As shown in Fig. S3, the lifetime of the $\mathrm{Eu}^{3+}$ excited state for Eu(ND) ${ }_{4} \mathrm{CTAC}$ complex is determined to be $0.98 \mathrm{~ms}$, and that for $\mathrm{Eu}(\mathrm{ND})_{4} \mathrm{CTAC} / \mathrm{EVA}$ film $(0.7 \%)$ is $0.96 \mathrm{~ms}$. Interestingly, the resultant films exhibit obviously red light even under daylight (Fig. 1c), while very strong luminescence is also observed upon illumination with $365 \mathrm{~nm}$ light source (Fig. 1d), which implies that this luminescent film shows promising prospect as a light-converting material in enhancing the PCE of Si-based solar cells.

The absorption spectra shown in Fig. 2 reveal that light transmittance of the film with $\mathrm{Eu}(\mathrm{ND})_{4} \mathrm{CTAC}$ complex $(0.2 \%)$ is higher than $82 \%$ in the visible light region. In addition, the transparency of the films slightly decreases in the visible region with the increase of complex amount. However, the transparency of luminescence films drastically declines in both the UV and visible light regions after the doping concentration exceeds $0.7 \%$, which is attributed to excessive aggregation of $\mathrm{Eu}(\mathrm{ND})_{4} \mathrm{CTAC}$ in EVA matrix. The morphologies of a series of films were studied by SEM. As shown in Fig. S4a-f, the surface morphology of the EVA film is almost uniform. When the EVA film is doped with $\mathrm{Eu}(\mathrm{ND})_{4} \mathrm{CTAC}$ complexes $(0.2 \%, 0.5 \%$ and $0.7 \%)$, there are many tiny and uneven protrusions on the surface. However, these protrusions' distribution becomes tighter to form agglomeration zones after the doping concentration of $\mathrm{Eu}(\mathrm{ND}){ }_{4} \mathrm{CTAC}$ complex exceeds $0.7 \%$, which suggests that increasing the doping concentration of $\mathrm{Eu}(\mathrm{ND})_{4} \mathrm{CTAC}$ complex easily promotes the $\mathrm{Eu}(\mathrm{ND})_{4} \mathrm{CTAC}$ complex to gather together and results in poor compatibility between the $\mathrm{Eu}(\mathrm{ND})_{4^{-}}$ CTAC complex and EVA matrix. This result is in consistent with the transmittance spectrum. The thickness of the film was estimated at about $141.6 \mu \mathrm{m}$ (Fig. S4g).

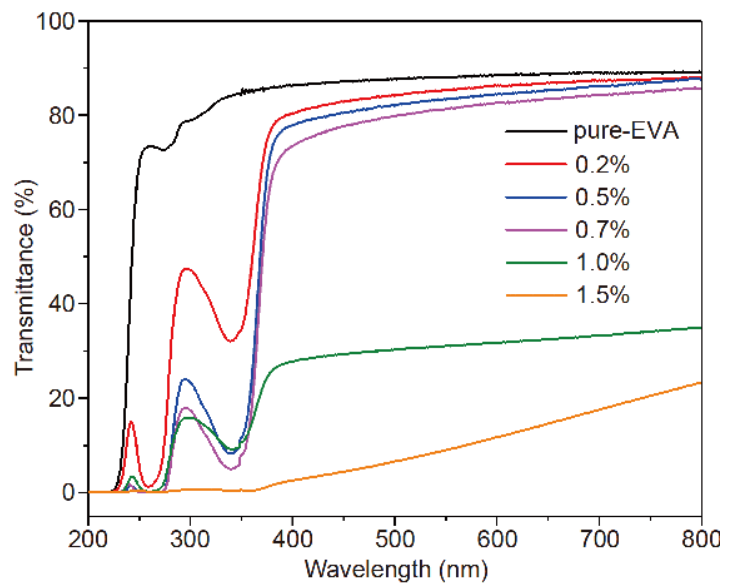

Figure $2 \mathrm{UV}$-vis transmittance spectra of pure EVA and $\mathrm{Eu}(\mathrm{ND})_{4^{-}}$ CTAC/EVA films with different concentrations of $\mathrm{Eu}(\mathrm{ND})_{4} \mathrm{CTAC}$.

Moreover, we also characterized the EDS mapping in order to further demonstrate the uniformity of $\mathrm{Eu}(\mathrm{ND})_{4^{-}}$ CTAC complex in EVA matrix (Fig. S4h). Considering the luminescence intensity and transparency of $\mathrm{Eu}(\mathrm{ND})_{4} \mathrm{CTAC} / \mathrm{EVA}$ films, the $0.7 \% \mathrm{Eu}(\mathrm{ND})_{4} \mathrm{CTAC}$ complex in EVA matrix can be considered as the optimal choice for application in Si-based solar cells.

In order to confirm the beneficial effect of $\mathrm{Eu}(\mathrm{ND})_{4}$ CTAC/EVA films on the photovoltaic response characteristic of polycrystalline silicon solar cells, the EQE measurement was carried out in the wavelength range from 300 to $1100 \mathrm{~nm}$. EQE is defined as the ratio between the number of charge carriers of the solar cell and the number of photons on its surface at each wavelength [16]. Measurements were taken after covering the photovoltaic module with a $\mathrm{Eu}(\mathrm{ND})_{4} \mathrm{CTAC} / \mathrm{EVA}$ film, as demonstrated in Fig. 3. In Fig. 4a, the EQE curves of a bare cell, and the cell covered with pure EVA film and $\mathrm{Eu}(\mathrm{ND})_{4^{-}}$

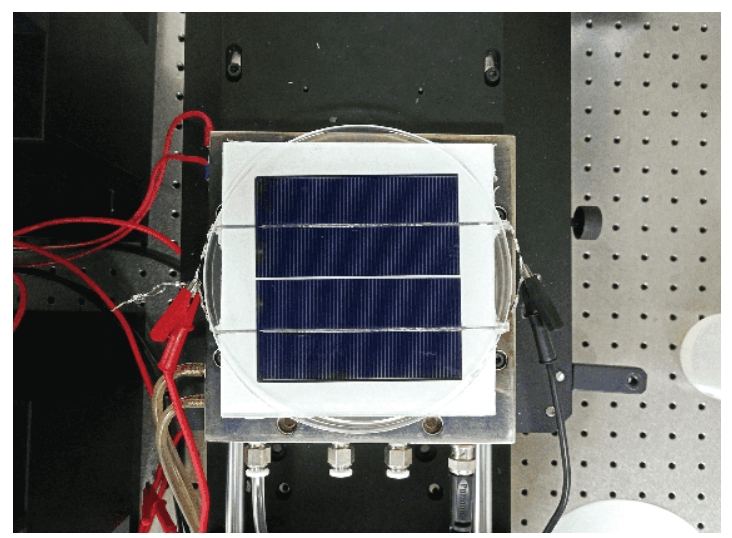

Figure 3 Si-based solar cell module coated with the luminescent film. 

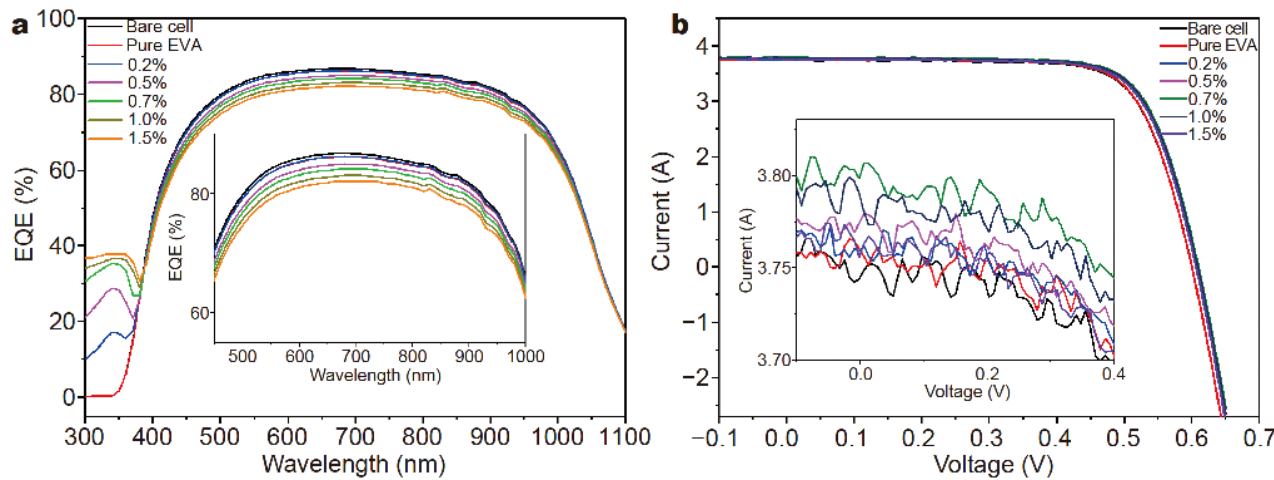

Figure 4 (a) The EQE curves of the bare cell, cell covered with pure EVA film and Eu(ND) ${ }_{4} C T A C / E V A$ films with different complex concentrations. (b) Current-voltage curves of the bare cell, cells covered with pure EVA film and Eu(ND) ${ }_{4}$ CTAC/EVA films with increasing complex concentration.

CTAC/EVA films with varying complex concentrations (from $0.2 \%$ to $1.5 \%$ ) are studied. For the setups with the cell uncoated and coated with pure EVA film, the EQE profiles are very similar, illustrating that the EQE effect of pure EVA film on the cell is negligible. However, the presence of the $\mathrm{Eu}(\mathrm{ND})_{4} \mathrm{CTAC}$ complex leads to an obvious $\mathrm{EQE}$ enhancement in the UV spectrum range from 300 to $370 \mathrm{~nm}$, which is ascribed to the photons undergoing down-shift via the lanthanide complex incorporated within the EVA films. On the other hand, the $\mathrm{EQE}$ of the cells coated with $\mathrm{Eu}(\mathrm{ND}){ }_{4} \mathrm{CTAC} / \mathrm{EVA}$ films in the visible region decreases gradually with the increase of the doping concentration from $0.2 \%$ to $1.5 \%$, with the effect possibly attributed to the photon absorption loss in visible wavelength range caused by the overall transparency decrease of the luminescent films $[33,38]$.

The photocurrent-voltage characteristic test was carried out under an AM 1.5G solar illumination at $100 \mathrm{~mW} \mathrm{~cm}^{-2}$ (1 sun) as shown in Fig. 4b. The detailed photovoltaic parameters such as short-circuit current density $\left(J_{\mathrm{SC}}\right)$, open-circuit photovoltage $\left(V_{\mathrm{OC}}\right)$, fill factor $(\mathrm{FF})$ and PCE derived from these curves are summarized in Table 1. All acquired data result from averaging the outcomes of 5 measurements each, to ensure the reliability of the obtained values. It is observed that the PCE displays an improvement (from $15.06 \%$ to $15.14 \%$ ) after coating with a pure EVA film in comparison with the bare cell, which mainly arises from the decrease of light reflection and some small error [33,39]. For the Eu (ND) ${ }_{4}$ CTAC/EVA films, the PCE prominently increases with the increase of doping concentration of the complex reaching a maximum at $0.7 \%$, which is then followed by a decrease (Fig. S5b). Furthermore, the $J_{S C}$ values show the similar variation trend (Fig. S5a). The decrease of performance might be caused by the fact that the severe diminishing transparency of the films $(1.0 \%$ and $1.5 \%)$ could obstruct the absorption of solar cells in the visible region, leading to the decrease of PCE, despite their increased EQE response in the ultraviolet region. As such, the optimal performance of a solar cell coated with the luminescent film is achieved when the concentration of the complex in the EVA film equals $0.7 \%$, in which case the value of PCE is increased from $15.06 \%$ to $15.57 \%$, with a relative increase by $3.42 \%$.

Table 1 Photovoltaic parameters of a bare cell, cells covered with pure EVA film and Eu(ND) ${ }_{4} \mathrm{CTAC} / \mathrm{EVA}$ films with different complex concentrations

\begin{tabular}{ccccc}
\hline $\begin{array}{c}\text { Silicon solar cell with and without } \\
\mathrm{Eu}(\mathrm{ND})_{4} \mathrm{CTAC} \text { coating }\end{array}$ & $V_{\mathrm{OC}}(\mathrm{V})$ & $J_{\mathrm{SC}}\left(\mathrm{mA} \mathrm{cm}{ }^{-2}\right)$ & FF $(\%)$ & PCE $(\%)$ \\
\hline Bare solar cell & $0.599 \pm 0.001$ & $34.14 \pm 0.02$ & $73.77 \pm 0.05$ & $15.06 \pm 0.01$ \\
Pure EVA film coating & $0.601 \pm 0.001$ & $34.16 \pm 0.09$ & $73.93 \pm 0.11$ & $15.14 \pm 0.02$ \\
$0.2 \% \mathrm{Eu}(\mathrm{ND})_{4} \mathrm{CTAC}$ in EVA & $0.606 \pm 0.001$ & $34.18 \pm 0.05$ & $74.16 \pm 0.04$ & $15.33 \pm 0.01$ \\
$0.5 \% \mathrm{Eu}(\mathrm{ND})_{4} \mathrm{CTAC}$ in EVA & $0.608 \pm 0.001$ & $34.36 \pm 0.08$ & $74.23 \pm 0.08$ & $15.47 \pm 0.02$ \\
$0.7 \% \mathrm{Eu}(\mathrm{ND})_{4} \mathrm{CTAC}$ in EVA & $0.610 \pm 0.001$ & $34.47 \pm 0.05$ & $74.22 \pm 0.08$ & $15.57 \pm 0.02$ \\
$1.0 \% \mathrm{Eu}(\mathrm{ND})_{4} \mathrm{CTAC}$ in EVA & $0.608 \pm 0.001$ & $34.43 \pm 0.09$ & $74.21 \pm 0.05$ & $15.51 \pm 0.01$ \\
$1.5 \% \mathrm{Eu}(\mathrm{ND})_{4} \mathrm{CTAC}$ in EVA & $0.605 \pm 0.002$ & $34.26 \pm 0.14$ & $74.09 \pm 0.10$ & $15.32 \pm 0.01$ \\
\hline
\end{tabular}


In addition to the excellent performance in terms of luminescent properties, high stability is highly desired for luminescent films to be successfully used in enhancing the efficiency of solar cells. Interestingly, the luminescent films investigated in this work show high thermal stability and remarkable photostability as shown in Fig. 5 and Fig. S6, respectively. From Fig. S6, it can be found that the thermal stability of the $\mathrm{Eu}(\mathrm{ND})_{4} \mathrm{CTAC} / \mathrm{EVA}$ film is higher than that of the pure EVA film and the main weight loss starts to occur at around $350^{\circ} \mathrm{C}$. The presence of the $\mathrm{Eu}(\mathrm{ND})_{4} \mathrm{CTAC}$ complex can apparently improve the thermostability of the EVA film. Fig. 5 reveals that the emission intensity of $0.7 \% \mathrm{Eu}(\mathrm{ND})_{4} \mathrm{CTAC} / \mathrm{EVA}$ film remains unchanged even after the film is subjected to a long-term accelerated aging at $30^{\circ} \mathrm{C}$ for $500 \mathrm{~h}$. No obvious changes in the quantum yield can be observed, with its value remaining constantly at about $52 \%$, unaffected by the long-term accelerated aging treatment. Moreover, the transparency of $\mathrm{Eu}(\mathrm{ND})_{4} \mathrm{CTAC} / \mathrm{EVA}$ film is also well maintained after the long-term UV light soaking test, as revealed in Fig. S7. These results demonstrate that $\mathrm{Eu}(\mathrm{ND})_{4} \mathrm{CTAC} / \mathrm{EVA}$ films possess the remarkable stability, namely strong resistance to photodegradation and high thermal stability.

\section{CONCLUSION}

In conclusion, a feasible method of increasing the PCE of polycrystalline silicon solar cells through spectra modification technology, achieved by employing a down-shift material (Eu(ND) ${ }_{4}$ CTAC complex) embedded in EVA matrix, was demonstrated. In the optimal case $(0.7 \%$ concentration of the complex in EVA matrix), the PCE of

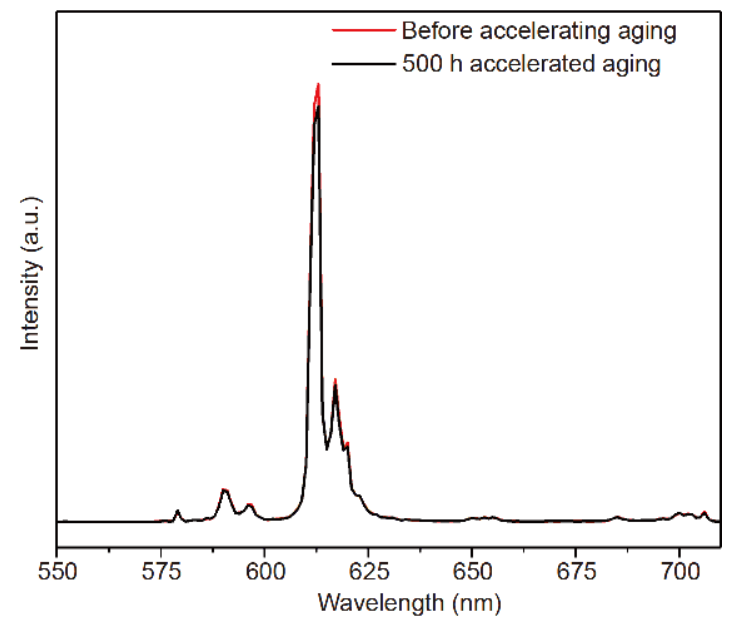

Figure 5 Emission spectra of the $\mathrm{Eu}(\mathrm{ND}){ }_{4} \mathrm{CTAC} / \mathrm{EVA}$ film $(0.7 \%$ concentration) before and after accelerated UV aging. the polycrystalline silicon solar cells coated with the luminescent film was improved from $15.06 \%$ to $15.57 \%$. Owing to the remarkable anti-photobleaching properties of the Eu(ND) ${ }_{4}$ CTAC complex, the Eu(ND) ${ }_{4}$ CTAC/EVA film displayed a highly satisfactory stability under the $500 \mathrm{~h}$ light soaking measurement. Therefore, the combination of favorable factors in the form of PCE enhancement and anti-photodegradation properties makes the $\mathrm{Eu}(\mathrm{ND}){ }_{4} \mathrm{CTAC} / \mathrm{EVA}$ film an attractive candidate for the development of low-cost and highly efficient photovoltaic devices.

Received 8 November 2019; accepted 3 January 2020;

published online 21 January 2020

1 Kabir E, Kumar P, Kumar S, et al. Solar energy: Potential and future prospects. Renew Sust Energ Rev, 2018, 82: 894-900

2 Lewis NS. Research opportunities to advance solar energy utilization. Science, 2016, 351: aad1920

3 Husain AAF, Hasan WZW, Shafie S, et al. A review of transparent solar photovoltaic technologies. Renew Sust Energ Rev, 2018, 94: 779-791

4 Parida B, Iniyan S, Goic R. A review of solar photovoltaic technologies. Renew Sust Energ Rev, 2011, 15: 1625-1636

5 Lian H, Hou Z, Shang M, et al. Rare earth ions doped phosphors for improving efficiencies of solar cells. Energy, 2013, 57: 270-283

6 Yu IS, Wu SC, Dumont L, et al. Monolithic crystalline silicon solar cells with SiN layers doped with $\mathrm{Tb}^{3+}$ and $\mathrm{Yb}^{3+}$ rare-earth ions. J Rare Earths, 2019, 37: 515-519

7 Fix T, Ferblantier G, Rinnert $\mathrm{H}$, et al. Evaluation of the effective quantum efficiency of photon conversion layers placed on solar cells. Sol Energ Mater Sol Cells, 2015, 132: 191-195

8 Wang HQ, Batentschuk M, Osvet A, et al. Rare-earth ion doped up-conversion materials for photovoltaic applications. Adv Mater, 2011, 23: 2675-2680

9 Yao N, Huang J, Fu K, et al. Rare earth ion doped phosphors for dye-sensitized solar cells applications. RSC Adv, 2016, 17546-17559

10 Strümpel C, McCann M, Beaucarne G, et al. Modifying the solar spectrum to enhance silicon solar cell efficiency-An overview of available materials. Sol Energ Mater Sol Cells, 2007, 238-249

11 Huang X, Han S, Huang W, et al. Enhancing solar cell efficiency: the search for luminescent materials as spectral converters. Chem Soc Rev, 2013, 42: 173-201

12 Zhou D, Liu D, Pan G, et al. Cerium and ytterbium codoped halide perovskite quantum dots: a novel and efficient downconverter for improving the performance of silicon solar cells. Adv Mater, 2017, 29: 1704149

$13 \mathrm{Xu} \mathrm{W}$, Song $\mathrm{H}$, Yan $\mathrm{D}$, et al. $\mathrm{YVO}_{4}: \mathrm{Eu}^{3+}, \mathrm{Bi}^{3+} \mathrm{UV}$ to visible conversion nano-films used for organic photovoltaic solar cells. J Mater Chem, 2011, 21: 12331-12336

14 Liu J, Wang $\mathrm{K}$, Zheng W, et al. Improving spectral response of monocrystalline silicon photovoltaic modules using high efficient luminescent down-shifting $\mathrm{Eu}^{3+}$ complexes. Prog Photovolt-Res Appl, 2013, 21: 668-675

15 Katsagounos G, Stathatos E, Arabatzis NB, et al. Enhanced photon harvesting in silicon multicrystalline solar cells by new lanthanide complexes as light concentrators. J Lumin, 2011, 131: 1776-1781

16 Chen $\mathrm{P}$, Shi J, Zhang Y, et al. EVA film doped with $\beta$-diketones 
macromolecular lanthanide complexes: Preparation, characterization and application. Eur Polym J, 2014, 58: 191-200

17 Le Donne A, Acciarri M, Narducci D, et al. Encapsulating $\mathrm{Eu}^{3+}$ complex doped layers to improve Si-based solar cell efficiency. Prog Photovolt-Res Appl, 2010, 17: 519-525

18 González-Pérez S, Sanchiz J, Rodríguez VD, et al. Highly luminescent film as enhancer of photovoltaic devices. J Lumin, 2018, 148-155

19 Li H, Li P. Luminescent materials of lanthanoid complexes hosted in zeolites. Chem Commun, 2018, 54: 13884-13893

20 Li Z, Wang G, Wang Y, et al. Reversible phase transition of robust luminescent hybrid hydrogels. Angew Chem Int Ed, 2018, 130: 2194-2198

21 Li Z, Hou Z, Fan H, et al. Organic-inorganic hierarchical selfassembly into robust luminescent supramolecular hydrogel. Adv Funct Mater, 2017, 27: 1604379

22 Wang Y, Li P, Wang S, et al. Recent progress in luminescent materials based on lanthanide complexes intercalated synthetic clays. J Rare Earths, 2019, 37: 451-467

23 Shahi PK, Singh AK, Singh SK, et al. Revelation of the technological versatility of the $\mathrm{Eu}(\mathrm{TTA})_{3}$ phen complex by demonstrating energy harvesting, ultraviolet light detection, temperature sensing, and laser applications. ACS Appl Mater Interfaces, 2015, 7: 1823118239

24 Monzón-Hierro T, Sanchiz J, González-Pérez S, et al. A new costeffective polymeric film containing an Eu(III) complex acting as UV protector and down-converter for Si-based solar cells and modules. Sol Energ Mater Sol Cells, 2015, 187-192

25 Zhang X, Wang T, Qin X, et al. Large-area flexible, transparent, and highly luminescent films containing lanthanide (III) complexdoped ionic liquids for efficiency enhancement of silicon-based heterojunction solar cell. Prog Photovolt Res Appl, 2017, 25: 10151021

26 Correia SFH, de Zea Bermudez V, Ribeiro SJL, et al. Luminescent solar concentrators: challenges for lanthanide-based organicinorganic hybrid materials. J Mater Chem A, 2014, 2: 5580-5596

27 Freitas VT, Fu L, Cojocariu AM, et al. Eu ${ }^{3+}$-based bridged silsesquioxanes for transparent luminescent solar concentrators. ACS Appl Mater Interfaces, 2015, 7: 8770-8778

28 Graffion J, Cattoën X, Wong Chi Man M, et al. Modulating the photoluminescence of bridged silsesquioxanes incorporating $\mathrm{Eu}^{3+}$ complexed $N, N^{\prime}$-diureido-2,2'-bipyridine isomers: application for luminescent solar concentrators. Chem Mater, 2011, 23: 47734782

29 Nolasco MM, Vaz PM, Freitas VT, et al. Engineering highly efficient $\mathrm{Eu}(\mathrm{III})$-based tri-ureasil hybrids toward luminescent solar concentrators. J Mater Chem A, 2013, 1: 7339-7350
Jiang L, Chen W, Zheng J, et al. Enhancing the photovoltaic per- formance of perovskite solar cells with a down-conversion Eucomplex. ACS Appl Mater Interfaces, 2017, 9: 26958-26964

31 Kettle J, Bristow N, Gethin DT, et al. Printable luminescent down shifter for enhancing efficiency and stability of organic photovoltaics. Sol Energ Mater Sol Cells, 2016, 144: 481-487

32 Tonezzer M, Maggioni G, Campagnaro A, et al. Luminescent solar concentrators employing new $\mathrm{Eu}(\mathrm{TTA})_{3}$ phen-containing parylene films. Prog Photovolt-Res Appl, 2015, 23: 1037-1044

33 Fix T, Nonat A, Imbert D, et al. Enhancement of silicon solar cells by downshifting with $\mathrm{Eu}$ and $\mathrm{Tb}$ coordination complexes. Prog Photovolt-Res Appl, 2016, 24: 1251-1260

34 Zhang H, Song H, Dong B, et al. Electrospinning preparation and luminescence properties of europium complex/polymer composite fibers. J Phys Chem C, 2008, 112: 9155-9162

35 Wei H, Zhao Z, Wei C, et al. Antiphotobleaching: A type of structurally rigid chromophore ready for constructing highly luminescent and highly photostable europium complexes. Adv Funct Mater, 2016, 26: 2085-2096

36 Le Donne A, Dilda M, Crippa M, et al. Rare earth organic complexes as down-shifters to improve Si-based solar cell efficiency. Opt Mater, 2011, 33: 1012-1014

37 Bünzli JCG. On the design of highly luminescent lanthanide complexes. Coord Chem Rev, 2015, 19-47

38 Fix $\mathrm{T}$, Rehspringer JL, Rinnert $\mathrm{H}$, et al. Functionalization of a polymer encapsulant with photon conversion. Sol Energ Mater Sol Cells, 2015, 133: 87-91

39 Jeong HJ, Kim YC, Lee SK, et al. Enhanced spectral response of CIGS solar cells with anti-reflective subwavelength structures and quantum dots. Sol Energ Mater Sol Cells, 2019, 194: 177-183

Acknowledgements This work was supported by the National Natural Science Foundation of China (21771050), the Natural Science Foundation of Hebei Province (B2016202147 and B2016202149), the Educational Committee of Hebei Province (LJRC021 and QN2015172), Hebei Province Natural Science Foundation (B2017202048), and Tianjin Natural Science Foundation (18JCYBJC17200).

Author contributions Wang $\mathrm{Y}$ and $\mathrm{Li} \mathrm{H}$ designed the experiments; Wang Y performed the experiments; Zhang X, Yin J and Wen Y helped with the photovoltaic measurement. Wang $\mathrm{Y}$ wrote the paper with support from Li H. Gawryszewska-Wilczynsk P helped modify the grammar. All authors contributed to the general discussion.

Conflict of interest The authors declare no conflict of interest.

Supplementary information Supporting data are available in the online version of the paper. 


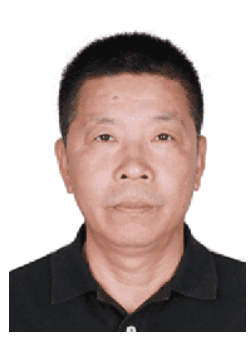

Huanrong Li received his $\mathrm{PhD}$ degree (2002) at Changchun Institute of Applied Chemistry, Chinese Academy of Sciences in the fields of functional materials based on lanthanide complexes. He spent 16 months at the Technical University of Munich under the Humboldt Fellowship. Afterwards, he initiated research on supramolecular chemistry of zeolite with Professor Gion Calzaferri at the University of Bern, Switzerland. In 2006, he was appointed as a full professor at the School of Chemical Engineering, Hebei University of Technology. His research interests and topics include luminescent host-guest functional materials and luminescent soft materials based on ionic liquids and lanthanides.

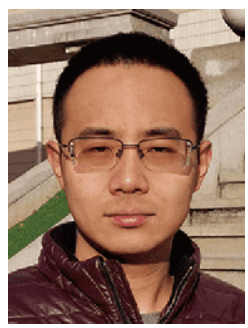

Yuan Wang received his Master's degree from Hebei University of Technology, China, in 2017. Currently he is pursuing Doctor's degree in Hebei University of Technology. His current research focuses on the application of rare earth luminescence materials.

\section{利用高度稳定的发光薄膜提高多晶硅太阳能电池 的光伏效率}

王元 ${ }^{1}$, Paula Gawryszewska-Wilczynsk ${ }^{2}$, 张秀荣 ${ }^{3,4}$, 尹健 ${ }^{3,4}$, 温永清 ${ }^{3,4}$, 李焕荣 $^{1 *}$

摘要 硅基太阳能电池已经主导了整个光伏市场, 但是仍然面临着 光电转化效率低的问题, 其中部分原因是其对紫外线的利用率较 低. 稀土铕配合物能够将紫外光转化为可见光, 有望提高硅基太阳 能电池的光电转化效率. 然而, 这类配合物较低的稳定性限制了它 们的实际应用. 本文中, 我们制备了一种高度稳定的EVA/Eu(ND) $4_{4}^{-}$ CT AC发光薄膜, 将其覆盖在大尺寸的多晶硅太阳能电池表面 $\left(110 \mathrm{~cm}^{2}\right)$ 可以使得光电转化效率从 $15.06 \%$ 提高到 $15.57 \%$. 在 $500 \mathrm{~h}$ 的加速老化实验中苂光性能几乎没有下降, 证明了发光薄膜的超 强稳定性. 在如此大的有效面积上, 发光薄膜使硅基太阳能电池的 转换效率提高 $0.51 \%$ 的绝对值, 同时实现超高的稳定性, 说明该发 光膜在光伏工业上具有广阔的应用前景. 